\title{
Aberrant caspase-activated DNase (CAD) transcripts in human hepatoma cells
}

\author{
SY Hsieh*, ${ }^{* 1,2}$, SF Liaw',3 , SN Lee ${ }^{3}$, PS Hsieh', KH Lin², CM Chu' and YF Liaw' \\ 'Liver Research Unit, Chang Gung Memorial Hospital, 199 Tung-Hua North Road, Taipei, Taiwan; ${ }^{2}$ Institute for Basic Medical Research, Chang Gung \\ University, Taoyuan; ${ }^{3}$ Department of Chemistry, Fu-Jen University, Hsin-Chuang, Taipei, Taiwan
}

\begin{abstract}
The gene of caspase-activated DNase (CAD), the key enzyme for nucleosome cleavage during apoptosis, is mapped at chromosome Ip36, a region usually associated with hemizygous deletions in human cancers, particularly in hepatoma (HCC). It is tempting to speculate that CAD plays a tumour-suppressive role in hepatocarcinogenesis. To address this, we examined the CAD transcripts in six human HCC cell lines, one liver tissue from a non-HCC subject, and peripheral blood leukocytes (PBL) from three healthy individuals. Alternatively spliced CAD transcripts with fusion of exon I to exon 7 were isolated in most of the examined samples including HCC cells and normal controls. However, relatively abundant alternatively spliced CAD transcripts with fusion of exon 2 to exon 6 or 7 , in which the corresponding domain directing CAD interaction with ICAD was preserved, were found only in poorly differentiated Mahlavu and SK-HepI cells. Interestingly, an abnormal CAD transcript with its exon 3 replaced by a truncated transposable Alu repeat was isolated in Hep3B cells, indicative of the implication of an Alu-mediated genomic mutation. Moreover, mis-sense mutations in the CAD genes were identified in all six HCC cell lines. Upon UV-induced apoptosis, DNA fragmentation efficiency was found to be intact, partially reduced and remarkably reduced in Huh7 and J328, Hep3B and HepG2, and Mahlavu cells, respectively. That mutations and aberrantly spliced transcripts for the CAD gene are frequently present in human HCC cells, especially in poorly differentiated HCC cells, suggests a significant role of CAD in human hepatocarcinogenesis.

British Journal of Cancer (2003) 88, 210 -216. doi:I0.1038/sj.bjc.6600695 www.bjcancer.com

(c) 2003 Cancer Research UK
\end{abstract}

Keywords: caspase-activated DNase; DNA fragmentation factor; DFF; DFF-B; apoptosis; hepatocellular carcinoma

Apoptosis is a programmed cell death process that removes toxic or useless cells during mammalian development (Wyllie, 1980). The biological hallmark of apoptosis is the cleavage of chromosomal DNA into nucleosomal fragments (Wyllie, 1980). Human caspase-activated DNase (CAD, also called DFF40/CPAN) is the key enzyme for nucleosome cleavage during cell apoptosis (Liu et al, 1997; Enari et al., 1998; Halenbeck et al, 1998; Mukae et al, 1998). CAD contains two different functional domains: the $\mathrm{N}$ terminal regulatory domain (CIDE-N or CAD domain) and the Cterminal catalytic domain. The CAD domain shares sequence homology with the N-terminal of the inhibitor of CAD (ICAD) (Liu et al, 1997; Mukae et al., 1998). Structural and mutational analyses of the CAD domains revealed that they account for the ability of CAD and ICAD to form a heterodimer (Inohara et al, 1999; Lugovskoy et al, 1999; Uegaki et al, 2000; Zhou et al, 2001). ICAD inhibits CAD activity by binding to CAD. During the apoptotic process, $C A D$ is released from the ICAD/CAD complex via proteocleavage of the ICAD by caspase 3 or caspase 7. CAD then degrades chromosomal DNA. Moreover, ICAD also works as a chaperon to help the correct folding of the CAD protein (Enari et al, 1998; Zhang et al, 1998; Sakahira et al., 1999). The active CAD can be synthesised only in the presence of ICAD both in vitro and in vivo. The $\mathrm{CAD}$ synthesised in vitro without ICAD does not have DNase activity at all.

*Correspondence: Dr SY Hsieh; E-mail: siming@adm.cgmh.com.tw Received 30 May 2002; revised 3 October 2002; accepted 9 October 2002
Inactivation of CAD has been shown to render cells resistant to undergoing apoptosis (Sakahira et al, 1998) and may cause cell transformation. Recently, human $C A D$ gene was mapped at chromosome 1p36.3 (Mukae et al, 1998). Human chromosome 1 p36 is frequently associated with hemizygous deletions in several types of cancers, particularly in hepatocellular carcinoma (HCC), indicating the presence of one or more tumour suppressor genes in the region (Buetow et al, 1989; Simon et al, 1991; Yeh et al, 1994). It is, therefore, tempting to speculate that CAD might be one of the tumour suppressors for hepatocellular carcinogenesis. To address this hypothesis, we examined the CAD transcripts in human HCC cells.

\section{MATERIALS AND METHODS}

\section{Hepatoma cell lines, liver tissue and peripheral leukocytes}

Human hepatoma cell lines, HepG2, Hep3B, Huh7, Sk-Hep1 (Fogh et al, 1977; Chang et al, 1993), and Mahlavu were obtained from American Type Culture Collection (Manassas, VA, USA), while J328 was kindly provided by Dr CS Yang (Chen et al, 1994). All media were supplemented with $10 \%(\mathrm{v} / \mathrm{v})$ foetal bovine serum and $2 \mathrm{~mm}$ L-glutamine. One non-HCC liver sample, obtained from a patient who received liver resection on account of a benign focal nodular hyperplasia of the liver, and peripheral blood leukocyte (PBL) samples obtained from three healthy individuals were included in the study as non-HCC controls. The liver sample was frozen immediately in liquid nitrogen after resection and stored at 
$-80^{\circ} \mathrm{C}$ until processing. The Ethics and Science Committee of Chang Gung Memorial Hospital approved specimen collection procedures and informed consent was obtained from each subject or subject's guardian.

\section{RNA preparation and RT-PCR}

Total cellular RNA was extracted from HCC cell lines, liver tissue and peripheral blood leukocytes using the single-step acid-phenol extraction method as described before (Lin et al, 2001). Total RNA $(2 \mu \mathrm{g})$ was converted to cDNA via a random-primer method as described previously (Hsieh et al, 1997). The whole reading-frame of the $C A D$ gene was cloned using nested PCR (Figure 1A). In brief, 1/50th of the cDNA was subjected to amplification for the first round of PCR in a total volume of $50 \mu \mathrm{l}$, which contained 4 pmol of each primer, $200 \mathrm{~nm}$ of each dNTP, and $2 \mathrm{U}$ of Taq DNA polymerase in a buffer containing $40 \mathrm{~mm}$ Tricine- $\mathrm{KOH}(\mathrm{pH} 8.7)$, $3.5 \mathrm{mM} \mathrm{MgCl}_{2}, 15 \mathrm{~mm}$ KOAc, $0.005 \%$ Tween-20 and $0.005 \%$ Nonidet-P40 (Advantage 2 PCR kit, CLONTECH, Palo Alto, CA, USA). Amplification was performed using 30 cycles of $95^{\circ} \mathrm{C}$ for $30 \mathrm{~s}, 65^{\circ} \mathrm{C}$ for $4 \mathrm{~min}$. The first-round PCR products were diluted $1 / 50$ and $1 \mu \mathrm{l}$ of the dilute was subjected to the second round of PCR with the inner primer pairs using conditions similar to that of the first-round PCR. After gel-electrophoresis analysis, the second-round PCR products were directly cloned using a PCR-TA cloning kit (pCRII TOPO, Invitrogen, Carlsbad, CA, USA). At least 10 clones derived from each HCC cell line and the liver sample, and at least five clones from each peripheral blood leukocyte samples were randomly selected for sequencing analysis. Sequencing analysis, using the two primers encoded in the vector and the two CAD-specific primers as illustrated in Figure 1a, was conducted as described before (Hsieh et al, 1999).

The primer sequences for the nested PCR were as follows:

First-round PCR: 5'-CCCAGAGGGCTTGAGGACATCTGCAA-3' $5^{\prime}$-ACCAGGACGTGGTGTGTACGTGTCA-3'

Second-round PCR: $5^{\prime}$-GAGGACATCTGCAATGCTCCAGAAGC- $3^{\prime}$ 5'-TCACTGGCGTTTCCGCACAGGCTG-3'

The sequences of the primers for sequencing are:

T7 primer:

SP6 primer:

CAD sense:

CAD antisense:

\section{5'-GTAATACGACTCGCTATAGGG-3'}

$5^{\prime}$-TATTTAGGTGACACTATAG-3'

$5^{\prime}$-GTGGTTTGAACGCTTGCAGTCCCCGA-3' $5^{\prime}$-GACCGGAGCCTCTGGCACGTGGA-3'

The nucleotide numbering used in this report is according to the numbering system by Mukae et al (1998) (GenBank accession numer: AB013918).

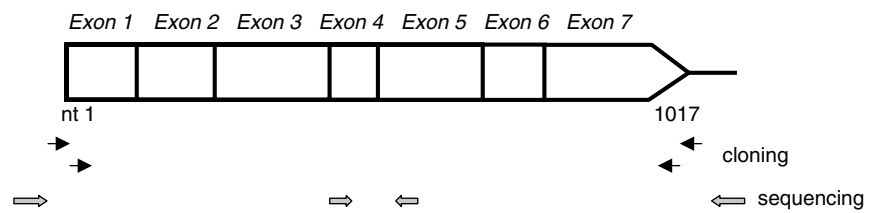

Figure I Schematic representation of the strategies for cloning and sequencing of the CAD cDNA. The CAD reading frame was cloned using nested RT-PCR method with two rounds of PCR following reverse transcription. Two primer pairs for amplification of the nested PCR are shown (arrows in both ends of the CAD reading frame). After examination with gel electrophoresis, the PCR products were cloned directly and then subjected to sequencing analysis using two vector primers (stippled arrows) flanking the cloning site and two CAD-specific primers (stippled arrows inside the reading frame).

\section{UV irradiation and DNA fragmentation}

At $24 \mathrm{~h}$ after plating $\left(2 \times 10^{6} / 100 \mathrm{~mm}\right.$ dish), cells were irradiated with $50-200 \mathrm{~mJ} \mathrm{~cm}^{-2}$ of UV and harvested for DNA fragmentation at $60,90,120,150,180$ and 210 min thereafter, respectively. PBSwashed cells were suspended in DNA extraction buffer containing $50 \mathrm{~mm}$ Tris $(\mathrm{pH} 8.0), 10 \mathrm{~mm}$ EDTA, $0.5 \% N$-laurosarcosine and $1 \mathrm{mg} \mathrm{ml}^{-1}$ proteinase $\mathrm{K}$, and incubated for $1 \mathrm{~h}$ at $50^{\circ} \mathrm{C}$ in a water bath. Then DNase-free RNase was added at a final concentration of $250 \mu \mathrm{g} \mathrm{ml}^{-1}$, at $50^{\circ} \mathrm{C}$ for another hour followed by ethanol precipitation of DNA. The DNA pellets were resuspended in TE buffer (10 mM Tris, pH 8.0/1 mM EDTA). DNA $(1 \mu \mathrm{g})$ was end labelled with $\alpha^{32} \mathrm{P}$-dATP in a solution containing $1 \mu \mathrm{g}$ DNA, 0.5 $\mathrm{mCi} \alpha^{32} \mathrm{P}$-dATP, $5 \mathrm{U}$ Klenow polymerase, $10 \mathrm{~mm}$ Tris, $\mathrm{pH}$ 7.5, $5 \mathrm{~mm}$ $\mathrm{MgCl}_{2}$ for $30 \mathrm{~min}$ at room temperature. The reaction was terminated by adding an equal volume of $10 \mathrm{~mm}$ EDTA. The labelled DNA was purified via a Sephadex G-50 spin-column (Pharmacia Biotech, Quarry Bay, Hong Kong), and analysed by electrophoresis on a $1 \%$ agarose gel and then by autoradiography. For quantification of DNA fragmentation upon UV-induced apoptosis in each HCC cell line, we used a cellular DNA fragmentation ELISA kit in accordance with the manufacturer's instruction (Roche Diagnostics GmbH, Mannheim, Germany). In brief, cells were metabolically labelled with $10 \mu \mathrm{m}$ of thymidine analogue BrdU for overnight. At $4 \mathrm{~h}$ after UV irradiation with 0 , 100 or $200 \mathrm{~mJ} \mathrm{~cm}^{-2}$, cell membrane was lysed for $30 \mathrm{~min}$ at $20^{\circ} \mathrm{C}$ in a solution containing $10 \mathrm{~mm}$ EDTA and $0.1 \%$ Tween-20. Following centrifugation for $10 \mathrm{~min}$ at $2500 \mathrm{~g}$ to remove cellular debris and nucleus component, the cytoplasmic lysate was subjected to an ELISA to detect fragmented DNA in cytoplasm.

\section{RESULTS}

To study abnormalities in the CAD transcripts in HCC, we reverse transcribed mRNA and amplified the complete CAD coding sequences by nested PCR (Figure 1). As illustrated in Figure 2, the 1-kb PCR products, which represented the full-length CAD transcripts, were detected in all the examined samples. Small PCR products, about $0.34 \mathrm{~kb}$, representing sub-full-length CAD transcripts were found in the non-HCC liver sample and in PBL from the three normal individuals (Figure $2 \mathrm{~B}$ ), whereas $0.45-\mathrm{kb}$ and 0.55-kb PCR products for sub-full-length CAD transcripts were detected in Mahlavu and SK-Hep1 cells, respectively (Figure 2A, lanes 5 and 6). The PCR products were directly cloned. At least 10 clones derived from each hepatoma cell line and non-HCC liver sample and at least five clones derived from each PBL sample were randomly selected for sequencing analysis. The sequencing results have been deposited in the GenBank and are summarised in Table 1.

The prototype transcripts were found in HepG2, Huh7 cells, non-HCC liver sample and the three PBL samples (Table 1). The full-length transcripts with single-nucleotide polymorphism (SNP) without change of amino acid were identified in J328 cells (wild type, in terms of amino-acid sequences). In addition, the fulllength transcripts with SNP leading to amino-acid changes (missense mutations) were noted in all of the 6 HCC cell lines (Table 1). All these mis-sense mutations corresponding to the CAD readingframe are illustrated in Figure 3. No hotspot for these mis-sense mutations in CAD was found, although most of them were located in the catalytic domain of CAD.

Sub-full-length transcripts were found in all of the six hepatoma cell lines (Figure 4A), even though sub-full-length transcripts were detected by gel electrophoresis only in Mahlavu and SK-Hep1 among the six examined HCC cell lines. In HepG2 cells, a minor sub-full-length transcript (one out of the 10 selected clones) with a deletion from nt 367 to nt 702 was identified. Of note, a fournucleotide identity, CTGC, was noted exactly at both of the $5^{\prime}$ - and $3^{\prime}$-deletion ends (nucleotides 367-370 and 703-706), suggesting 

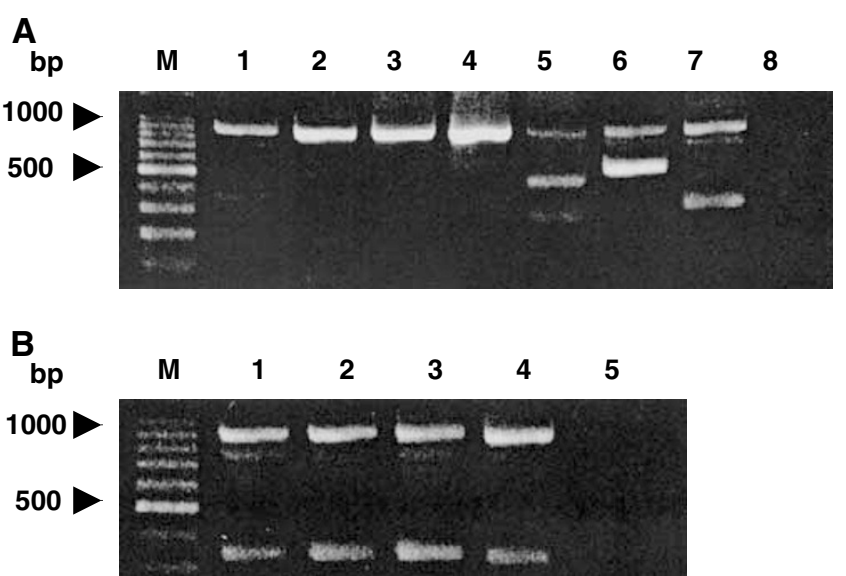

Figure 2 Expression of the CAD gene by nested RT-PCR. After reverse transcription, the samples derived from six HCC cell lines were subjected to two rounds of PCR as described in the legend of Figure I. (A) Lanes I8 represent the size marker, the PCR products derived from HepG2, Hep3B, Huh7, J328, Mahlavu, SK-Hep I cells and the non-HCC liver sample, respectively. Of note, HepG2 and Hep3B are well-differentiated HCC cells, Huh7 and 1328 are moderately differentiated HCC cells, and Mahlavu and SK-Hep I are poorly differentiated HCC cells. (B) Lanes I -5 represent the $\mathrm{PCR}$ products derived from the non-HCC liver sample and from the three PBL samples and a negative control for PCR respectively. involvement of a recombination deletion. In Hep3B cells, an aberrant CAD transcript (three out of the 10 clones) corresponded to replacement of exon 3 with a 121-base sequence, which was homologous to part of the human transposon, Alu repeat. In both Huh7 and J328 cells, there were minor small transcripts (two and one out of the 10 clones, respectively) with the absence of exons $2-$ 6 resulting in conjunction of exon 1 to exon 7, suggestive of transcripts derived from an alternative splicing process. Similar alternatively spliced CAD transcripts with fusion of exon 1 to exon 7 were also noted in the non-HCC liver tissue and the three PBL samples as well (Figure 2B and Table 1). In Mahlavu and SK-Hep1 cells, relatively abundant alternatively spliced transcripts (three and seven out of the 10 clones, respectively) coincided with the absence of exons 3 to 6 , or to 5 leading to fusion of exon 2 to exon 7 or 6 , respectively (Table 1 and Figure 4A).

The predicted amino-acid sequences for these aberrant transcripts are aligned to that of the prototype CAD and shown in Figure $4 \mathrm{~B}$. Of note, the amino-acid sequences for CAD domain (aa $1-80$ ) were preserved in the aberrant CAD transcripts identified in HepG2, Hep3B, Mahlavu and SK-Hep1 cells.

To inspect the nucleosome cleavage activity of CAD during apoptosis in these HCC cell lines, DNA fragmentation assay was conducted after UV induction of apoptosis. As shown in Figure 5, the relative efficiency of DNA fragmentation upon UV irradiation in HepG2, Hep3B, Huh7, J328 and Mahlavu cells was 0.56-, 1.26-, $1.60-, 1.81-$ and 0.87 -fold, respectively, as compared to that in

Table I Variants of CAD CDNA in human HCC cell lines, non-HCC liver tissue and PBL

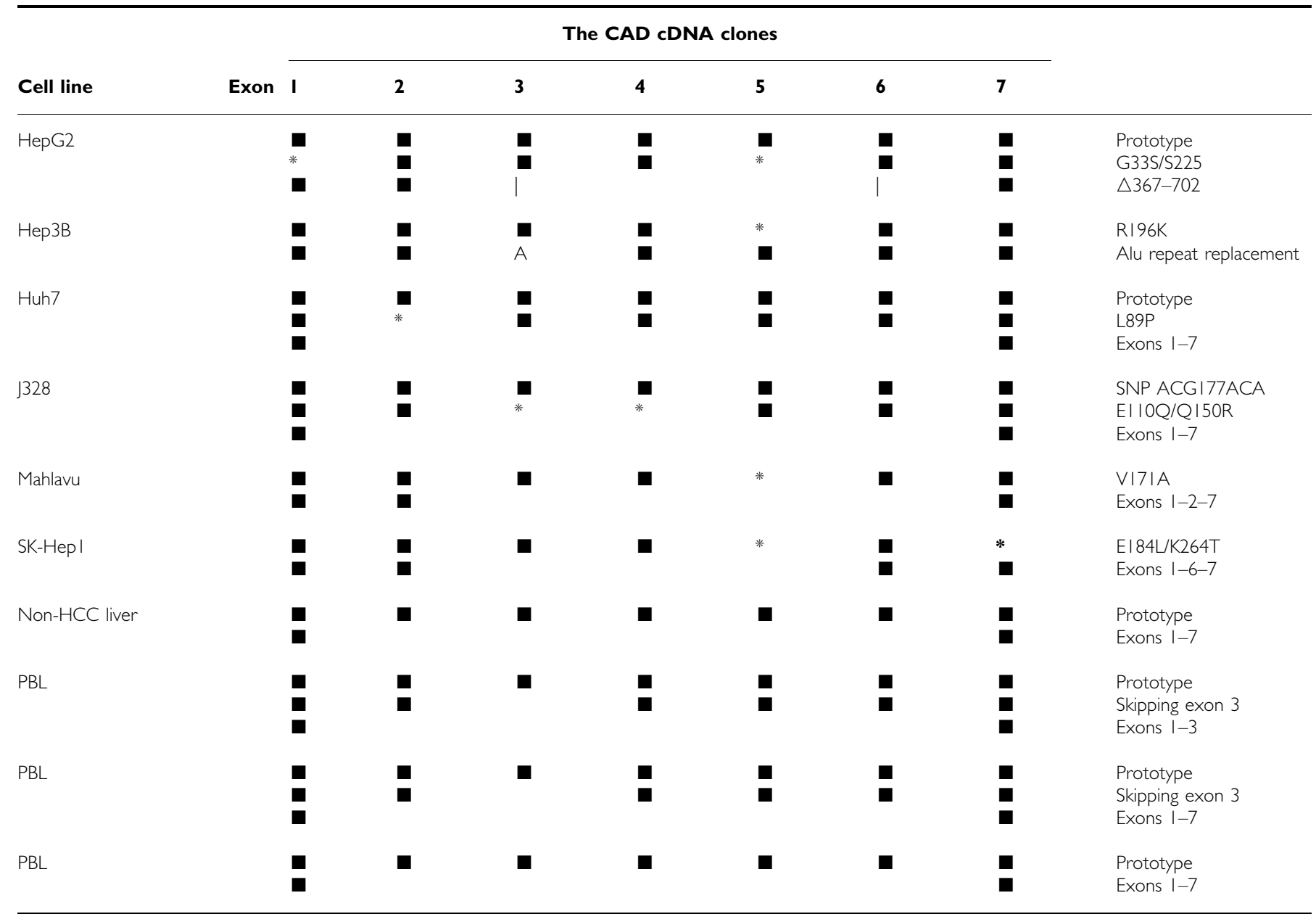

*: mis-sense mutation; A: the Alu repeat; $\triangle$ : deletion with CTGC repeats at both ends; I: incomplete exon sequences. 


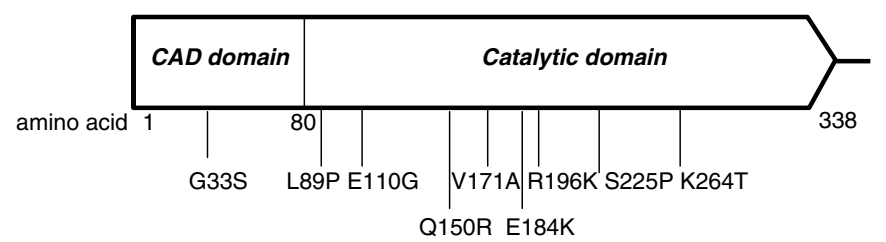

Figure 3 Scheme of mapping the mis-sense mutations to the corresponding CAD reading frame. Amino acids $\mathrm{I}-80$ is the CIDE-N or CAD domain that directs interaction with ICAD; the C-terminal is the catalytic domain containing nuclease activity.

HeLa cells. The relative inefficiency of DNA fragmentation upon UV irradiation in HepG2 cells was attributable to a relatively low susceptibility to UV-induced apoptosis (data not shown).

\section{DISCUSSION}

Herein we report the identity of aberrant CAD transcripts in human HCC cells. Two classes of human CAD cDNA have been cloned by Mukae et al (1998). One encompasses the entire coding region, whereas the other contains many deletions, insertions and point mutations in the corresponding coding region. The latter is thought to be derived from a pseudogene (Mukae et al, 1998). Obviously, the subfull-length CAD cDNAs reported herein were not derived from pseudogenes. Instead, most of them were more likely generated via aberrant RNA processing mechanisms.

The minor CAD transcript (representing one out of the 10 isolated CAD cDNA clones) in HepG2 cells with a deletion from nucleotides 367 to 702 possibly resulted from a recombination processing, because of a four-nucleotide identity, CTGC, noted exactly in both the deletion ends (nucleotides 367-370 and 702705 , respectively). Two different species of full-length CAD transcripts, a prototype and a transcript with mis-sense mutations, were identified, suggesting that the recombination occurs more

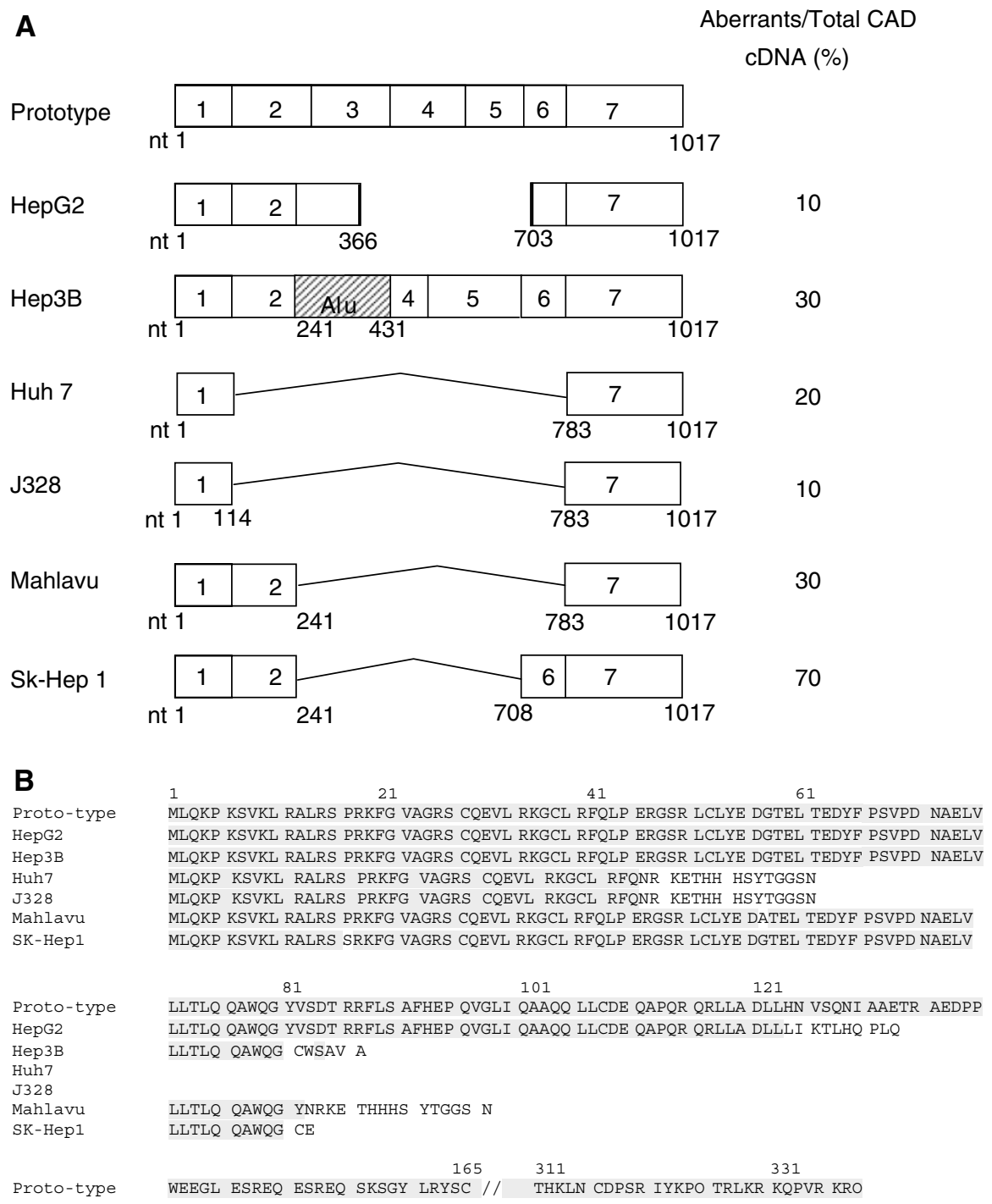

Figure 4 Scheme of the aberrant CAD transcripts and their predicted proteins. (A) The coding exons I -7 are demonstrated as open squares. The heavy lines in the transcripts in HepG2 cells represent a four-nucleotide identity at the two skipping ends (nucleotides 367-370 and 702-705, in accordance with the numbering system by Mukae et al (1998)). The box labelled with 'Alu' in Hep3B cells represents a sequence homologous to a human Alu repeat. (B) Alignment of the predicted amino-acid sequences for the aberrant CAD transcripts to the prototype CAD amino-acid sequences (Mukae et al, I998). Note that CAD domain (aa I-80) is preserved in the aberrant transcripts from HepG2, Hep3B, Mahlavu and SK-Hep I cells. 
214

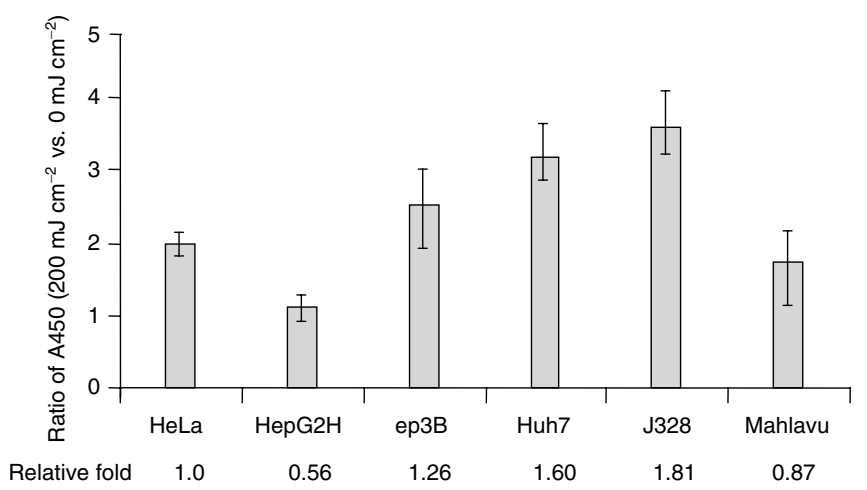

Figure 5 ELISA for cellular DNA fragmentation. After 0,100 or $200 \mathrm{~mJ} \mathrm{~cm}^{-2}$ of UV irradiation, cytoplasmic lysate of cells containing DNA metabolically prelabelled with BrdU was subjected to an ELISA with antiDNA antibody binding to fragmented DNA in cytoplasm followed by quantification with a peroxidase-conjugated anti-BrdU antibody (Roche Diagnostics GmbH, Mannheim, Germany). The representative results were derived from experiments conducted in a manner of duplication for each sample in every assay in a total of three assays. The averages and ranges of the ratio of DNA fragmentation before vs after UV irradiation for each cell line are illustrated. The relative amount of DNA fragmentation for each $\mathrm{HCC}$ cell line was determined via comparison to that for HeLa cells.

likely during mRNA processing than at the chromosomal DNA level (Table 1).

The sub-full-length CAD transcript (representing three out of the 10 isolated CAD cDNA clones) corresponding to replacement of exon 3 with a truncated human transposon, Alu repeat, was isolated in Hep3B cells. Alu elements are a specific human family of interspersed repetitive sequences. It was estimated to be over 1000000 copies per genome. Their dispersion and plethora is attributable to transposition via a mechanism that has not been fully understood yet (Mathias et al, 1991). It was likely that the CAD transcript with replacement of exon 3 with the Alu element reported herein was generated via an $A l u$-mediated genomic mutation mechanism. One possible mechanism is that a de novo $A l u$-insertion mutation occurs in one of the two alleles of the $C A D$ gene. In theory, mobilization of Alu elements requires a cellular source of reverse transcriptase that is generally believed to be provided by a concurrently activated retrotransposon, such as LINE-1 elements (Mathias et al, 1991). Indeed, global DNA demethylation has been generally found in human cancers including HCC (Lin et al, 2001), which in turn leads to activation of transposable elements, such as LINE-1 and Alu repeats. It is, therefore, conceivable to speculate that mutations secondary to transposition of transposons in human cancers may not be rare events. Indeed, de novo Alu insertion leading to human diseases, particularly in tumours, has been reported before (Kazazian, 1998). For examples, the insertions cause heamophilia B (factor IX gene) (Vidaud et al, 1993), neurofibromatosis (NF-1 gene) (Walllace et al, 1991), Apert syndrome (FGFR2 gene), acholinesterasemia (ChE gene) (Muratani et al, 1991), desmoid tumors (APC gene) and breast cancer (Katagiri and Nakamura, 1996) (see the review by Kazazian, 1998). Alternatively, this Alu-containing CAD transcript might result from an Alu/Alu homologous recombination/deletion, which led to exon 3 deletion and activation of a cryptic splicing acceptor site in Alu elements. Experiments to elucidate the roles of $A l u$-elements in genomic mutations for the $C A D$ gene are in progress.

On the other hand, the sub-full-length CAD transcripts found in Huh7 and J328 cells exhibited loss of exons 2-6 and resulted in fusion of exons 1 and 7 . Since the fusion junctions just coincided with the splice sites, they must be generated via alternative splicing processes. Similar alternative spliced transcripts with fusion of exons 1-7 were also found in the liver tissue from a non-HCC subject and in the PBL from three healthy individuals. The CAD reading frame encoded by these small transcripts was so greatly disrupted that they might not have any biological significance.

By contrast, the sub-full-length CAD transcripts found in poorly differentiated HCC cells, Mahlavu and SK-Hep1, corresponded to the absence of exons 3 to 6 or 5 and created a junction between exon 2 to exon 7 or 6 , respectively. Apparently, they were generated via aberrant splicing mechanisms. These transcripts are of great interest because not only were they cancer specific (only found in poorly differentiated Mahlavu and SK-Hep1 cells) and relatively abundant (30 and $70 \%$ of the isolated CAD cDNA clones, respectively), but they also preserved the CAD domain (aa 1-80) directing CAD interaction with its inhibitor (ICAD) (Mukae et al, 1998; Uegaki et al, 2000, Otomo et al, 2000). Since ICAD functions as a chaperon for the regulation of CAD activity (Enari et al, 1998; Sakahira et al, 1998; Sakahira et al, 2000), these predicted aberrant CAD products might sequester ICAD from interacting with the wild-type $\mathrm{CAD}$, thereby preventing the correct folding of $\mathrm{CAD}$ and subsequently blocking the nuclease activity of the wild-type CAD in the cells. Interference of the CAD activity renders cells more resistant to cell death, and in turn may award cells with advantages for survival and, possibly, for carcinogenesis (Sakahira et al, 1998). It is, therefore, intriguing to speculate that these aberrant CAD products encoded by the aberrant CAD transcripts in SK-Hep1 and Mahlavu cells (and those in HepG2 and Hep3B cells, Figure 4A and B) play significant roles in cell apoptosis and in hepatocarcinogenesis. Indeed, in the experiments for DNA laddering under UVinduced apoptosis, the phenomenon of DNA laddering was remarkably impaired in Mahlavu and SK-Hep1 cells, and partially impaired in HepG2 and Hep3B cells, as compared to that in HeLa, Huh7 and J328 cells. Studies to further dissect the effects of these $\mathrm{C}^{\prime}$ - truncated CAD on nucleosome cleavage activities of the wildtype CAD are currently ongoing.

Alternative splicing has been regarded as an important mechanism that contributes to genetic diversity by generating multiple protein isomers from a single gene (Croft et al, 2000; Mironov et al, 2000). However, alternative splicing can also lead to human disease (Blencowe, 2000; Philips and Cooper, 2000). Alterations in alternative splicing of certain pre-mRNA have recently been correlated to either neoplastic transformation and/or acquisition of metastatic potential (Savagner et al, 1994; Cooper and Dougherty, 1995; Barrack, 1996; Pfeffer, 1996; Skuse and Cappione, 1997; Iwase et al, 1998; Philips and Cooper, 2000). Most of these altered splicing patterns are because of either changes in trans-acting factors or mutations within the canonical sequences at the intro/exon border that are required for splicing. However, mutations in an auxiliary element required for pre-mRNA splicing within exons were found more recently. It was reported that in human neuroblastomas, ataxia telangiectasia and breast cancer some nonsense mutations caused skipping of exons, a phenomenon known as nonsense-associated altered splicing (Teraoka et al, 1999; Ars et al, 2000; Hastings and Krainer, 2001; Liu et al, 2001). The latter was attributable to result from non-sense mutations in exon leading to disrupting a splicing enhancer in exon, which contains recognition sequences for splicing factors, such as SF2/ASF (Coulter et al, 1997; Hastings and Krainer, 2001; Liu et al, 2001). The exon-skipping phenotype has been reproduced in vitro and was shown not to result from disruption of the translational reading frame (Blencowe, 2000). The canonical sequences at the intron-2/exon3 junction and the coding sequences in exon 3 for the CAD genes in Hep3B, Mahlavu and SK-Hep1 cells have been examined. However, neither mutations to disrupt the intro/exon sequence nor non-sense mutations in exon 3 was found (data not shown). Further studies to elucidate the underlying molecular mechanism 
for altered alternative splicing for the $C A D$ gene in HCC are warranted.

In summary, we report the identity of aberrant transcripts and frequent mutations for the CAD gene in human HCC cells, suggesting a significant role of $\mathrm{CAD}$ in human hepatocarcinogenesis.

\section{REFERENCES}

Ars E, Serra E, Garcia J, Kruyer H, Gaona A, Lazaro C, Estivill X (2000) Mutations affecting mRNA splicing are the most common molecular defects in patients with neurofibromatosis type 1. Hum Mol Genet 9: $237-247$

Barrack ER (1996) Androgen receptor mutations in prostate cancer. $M t$ Sinai J Med 63: 403-412

Blencowe BJ (2000) Exonic splicing enhancers: mechanism of action, diversity and role in human genetic diseases. Trends Biochem Sci 25: 106-110

Buetow KH, Murray JC, Israel JL, London WT, Smith M, Kew M, Blanquet V, Brechot C, Reder A, Govindarajah S (1989) Loss of heterozygosity suggests tumor suppressor gene responsible for primary hepatocellular carcinoma. Proc Natl Acad Sci, USA 86: 8852-8856

Chang KSS, Hsu MI, Josphs SF (1993) Regulation of HIV-1 LTR transactivating activities in two different human hepatocellular carcinoma cell ines. Cancer Lett 74: 75-83

Chen MR, Hsu TY, Chou MJ, Chang ACW, Chen JY, Yang CS (1994) Stability of HBV DNA in cell lines and nude mouse-passaged tissues derived from human hepatocellular carcinoma. Chinese J Microbiol Immunol 27: 1-12

Cooper DL, Dougherty GJ (1995) To metastasize or not? Selection of CD44 splice sites. Nature Med 1: 635-637

Coulter LR, Landree MA, Cooper TA (1997) Identification of a new class of exonic splicing enhancers by in vivo selection. Mol Cell Biol 17: $2143-2150$

Croft L, Schandorff S, Clark F, Burrage K, Arctander P, Mattick JS (2000) ISIS, the intron information system, reveals the high frequency of alternative splicing in the human genome. Nat Genet 24: 340-341

Enari M, Sakahira H, Yokoyama H, Okawa K, Iwamatsu A, Nagata SA (1998) caspase-activated DNase that degrades DNA during apoptosis and its inhibitor ICAD. Nature 391: $43-50$

Fogh J, Fogh J, Orfeo T (1977) One hundred and twenty-seven cultured human tumor cell lines producing tumors in nude mice. J Natl Cancer Inst 59: $221-225$

Halenbeck R, MacDonald H, Roulston A, Chen TT, Conroy L, Williams LT (1998) CPAN, a human nuclease regulated by the caspase-sensitive inhibitor DFF45. Curr Biol 8: 537 - 540

Hastings ML, Krainer AR (2001) Pre-mRNA splicing in the new millennium. Curr Opin Cell Biol 13: $302-309$

Hsieh SY, Meng XJ, Wu YH, Liu ST, Tam AW, Lin DY, Liaw YF (1999) Identity of a novel swine hepatitis $\mathrm{E}$ virus in Taiwan forming a monophyletic group with Taiwan isolates of human hepatitis E virus. $J$ Clin Microbiol 37: 3828-3834

Hsieh SY, Yang PY, Chen HC, Liaw YF (1997) Cloning and characterization of the extreme 5'-terminal sequences of the RNA genomes of GB virus C/hepatitis G virus. Proc Natl Acad Sci, USA 94: $3206-3210$

Inohara N, Koseki T, Chen S, Benedict MA, Nunez G (1999) Identification of regulatory and catalytic domains in the apoptosis nuclease DFF40/CAD. Journal of Biological Chemistry 274: $270-274$

Iwase H, Omoto Y, Iwata H, Hara Y, Ando Y, Kobayashi S (1998) Genetic and epigenetic alterations of the estrogen receptor gene and hormone independence in human breast cancer. Oncology 55: 11-16

Kazazian Jr HH (1998) Mobile elements and disease. Curr Opin Genet Dev 8: $343-350$

Lin CH, Hsieh SY, Sheen IS, Lee WC, Chen TC, Shyu WC, Liaw YF (2001) Genome-wide hypomethylation in hepatocellular carcinogenesis. Cancer Res 61: $4238-4243$

Liu HX, Cargegni L, Zhang MQ, Krainer AR (2001) A mechanism for exon skipping caused by nonsense or missense mutations in BRCA1 and other genes. Nat Genet 27: 55-58

Liu X, Li P, Widlak P, Zou H, Luo X, Garrard WT, Wang X (1998) The 40$\mathrm{kDa}$ subunit of DNA fragmentation factor induces DNA fragmentation

\section{ACKNOWLEDGEMENTS}

The authors are grateful to Su-Chen Ji for her expertise in graph drawing. This work was supported in part by a grant from Chang Gung Memorial Hospital and a grant from National Science Council, Taiwan. and chromatin condensation during apoptosis. Proc Natl Acad Sci, USA 95: $8461-8466$

Liu X, Zou H, Slaughter C, Wang X (1997) DFF, a heterodimeic protein that functions downstream of caspase-3 to trigger DNA fragmentation during apoptosis. Cell 89: $175-184$

Lugovskoy AA, Zhou P, Chou JJ, McCarty JS, Li P, Wagner G (1999) Solution structure of the CIDE-N domain of CIDE-B and a model for CIDE-N/CIDE-N interactions in the DNA fragmentation pathway of apoptosis. Cell 99: $747-755$

Mathias SL, Scott AF, Kazazian Jr HH, Boeke JD, Gabriel A (1991) Reverse transcriptase encoded by a human transposable element. Science 254: $1808-1810,1991$

Mironov AA, Fickett JW, Gelfand MS (1999) Frequent alternative splicing of human genes. Genome Res 9: $1288-1293$

Mukae N, Enari M, Sakahira H, Fukuda Y, Inazawa J, Toh H, Nagata S (1998) Molecular cloning and characterization of human caspaseactivated DNase. Proc Natl Acad Sci, USA 95: 9123-9128

Muratani K, Hada T, Yamamoto Y, Kaneko T, Shigeto Y, Ohue T, Furuyama J, Higashimo K (1991) Inactivation of the cholinesterase gene by Alu insertion: possible mechanism for human gene transposition. Proc Natl Acad Sci USA 88: $11315-11319$

Otomo T, Sakahira H, Uegaki K, Nagata S, Yamazaki T (2000) Structure of the heterodimeric complex between CAD domains of CAD and ICAD. Nat Structu Biol 7: 658-662

Pfeffer U (1996) Estrogen receptor mRNA variants. Do they have a physiological role? Ann NY Acad Sci 784: 304-311

Philips AV, Cooper TA (2000) RNA processing and human disease. Cell Mol Life Sci 57: 235-249

Sakahira H, Enari M, Nagata S (1998) Cleavage of CAD inhibitor in CAD activation and DNA degradation during apoptosis. Nature 391: 96-99

Sakahira H, Enari M, Nagata S (1999) Functional differences of two forms of the inhibitor of caspase-activated DNase, ICAD-L, and ICAD-S. J Biol Chem 274: 15740 - 15744

Sakahira H, Iwamatsu A, Nagata S (2000) Specific chaperone-like activity of inhibitor of caspase-activated DNase for caspase-activated DNase. J Biol Chem 275: $8091-8096$

Savagner P, Valles AM, Jouanneau J, Yamada KM, Thiery JP (1994) Alternative splicing in fibroblast growth factor receptor 2 is associated with induced epithelial-mesenchymal transition in rat bladder carcinoma cells. Mol Biol Cell 5: $851-862$

Simon D, Knowles BB, Weith A (1991) Abnormalities of chromosome 1 and loss of heterozygosity on $1 \mathrm{p}$ in primary hepatoma. Oncogene 6: $765-770$

Skuse GR, Cappione AJ (1997) RNA processing and clinical variability in neurofibromatosis type 1 (NF1). Human Mol Genet 6: 1707-1712

Teraoka SN, Telatar M, Becker-Catania S, Liang T, Onengut S, Tolun A, Chessa L, Sanal O, Bernatomska E, Gatti RA, Concannon P (1999) Slicing defects in the ataxia-telangiectasia gene, ATM: underlying mutations and consequences. Am J Hum Genet 64: 1617-1631

Uegake K, Otomo T, Sakahira H, Shimizu M, Yumoto N, Kyogoku Y, Nagata S, Yamazaki T (2000) Structure of the CAD domain of caspaseactivated DNase and interaction with the CAD domain of its inhibitor. $J$ Mol Biol 297: $1121-1128$

Vidaud D, Vidaud M, Bahnak BR, Siguret V, Gispert Sanchez S, Laurian Y, Meyer D, Goossens M, Lavergne JM (1993) Hemophilia B due to a de novo insertion of a human-specific Alu subfamily member within the coding region of the factor IX gene. Eur J Hum Genet 1: 30-36

Walllace MR, Andersen LB, Saulino AM, Gregory PE, Glover TW, Collins FS (1991) A de novo Alu insertion results in neurofibromatosis type 1 . Nature 353: $864-866$.

Wyllie AH (1980) Glucocorticoid-induced thymocyte apoptosis is associated with endogenous endonuclease activation. Nature 284: 555-556 
Yeh SH, Chen PJ, Chen MY, Lai MY, Wang CC, Chen DS (1994) Frequent genetic alternations at the distal region of chromosome $1 \mathrm{p}$ inhuman hepatocellular carcinomas. Cancer Res 54: 4188-4192

Zhang J, Liu X, Scherer DC, Kaer LV, Wang X, Xu M (1998) Resistance to DNA fragmentation and chromatin condensation in mice lacking the DNA fragmentation factor 45. Proc Natl Acad Sci USA 95: 8461-8466
Zhou P, Lugovskoy AA, McCarty JS, Li P, Wagner G (2001) Solution structure of DFF40 and DFF45 N-terminal domain complex and mutual chaperone activity of DFF40 and DFF45. Proc Natl Acad Sci USA 98: $6051-6055$ 